\title{
Periodismo especializado y especialización política
}

\author{
Specialized journalism and political specialization
}

\author{
Salvador ENGUIX OLIVER \\ Universitat de València - España \\ Salvador.Enguix@uv.es
}

Cómo citar este artículo: ENGUIx OLIVER, Salvador (2015): «Periodismo especializado y especialización política», Mediaciones Sociales, no 14, pp. 103-128. DOI: http://dx.doi.org/10.5209/rev_MESO.2015.n14.51561

Recibido: 30 de diciembre de 2014.

Aceptado: 14 de octubre de 2015.

\section{RESUMEN}

En este artículo se revisa la bibliografía sobre periodismo especializado y se analizan los rasgos normalmente aducidos para identificar la especialización periodística, que apuntan por lo general al contenido de los textos: la especificidad temática, el enfoque en profundidad, la metodología de investigación, el recurso a fuentes expertas, la necesidad de formación complementaria a la propiamente periodística, la orientación a audiencias segmentadas, el uso de géneros textuales concretos, o la adecuación lingüística. La aplicación de estos mismos factores a la especialización política pone de manifiesto la necesidad de cuestionar los rasgos aducidos y considerar otros criterios en el concepto de especialización, referidos principalmente a las rutinas profesionales de producción. Se propone que en la especialización política es la propia praxis profesional, con sus particularidades y características (relación con las fuentes, conocimiento del sistema y las instituciones), la que determina la propia especialización del área y del profesional.

PALABRAS CLAVE: fuentes periodísticas, periodismo especializado, periodismo político, rutinas profesionales periodísticas.

\section{ABSTRACT}

This paper reviews the literature on specialized journalism and the traits usually alleged to identify journalistic expertise, normally referred to the content of the texts: thematic specificity, focus in 
depth, research methodology, use of expert sources, need for additional training for the journalist, segmented hearings, specific textual genres, and linguistic appropriateness. Applying the same factors to political specialization highlights the need to question those traits and consider other criteria in the concept of specialization, referring primarily to professional production routines. It is proposed that in political specialization is the professional practice itself, with its peculiarities and characteristics (relation with sources, knowledge of the system and institutions), which determines the specialization.

KEYWORDS: journalistic sources, specialized journalism, political journalism, professional routines of journalism.

Sumario: 1. Planteamiento y objetivos. 2. Las variables definitorias del periodismo especializado. 2.1. Especificidad/coherencia temática. 2.2. Enfoque en profundidad y metodología de investigación. 2.3. El recurso a fuentes expertas y la formación de periodistas expertos. 2.4. Audiencias segmentadas. 2.5. Idoneidad lingüística y de género textual. 3. La especialización en periodismo político. 3.1. La importancia del periodismo político. 3.2. Identidad temática (y funcional) del periodismo político. 3.3. Formación y conocimiento experto del periodista político. 3.4. Las fuentes en el periodismo político. 3.5. Metodología en la producción de noticias y tratamiento en profundidad. 3.6. Las rutinas profesionales en el periodismo político. 3.7. Audiencias especializadas. 3.8. Los géneros del periodismo político. 4. Conclusiones. Bibliografía.

\section{PLANTEAMIENTO Y OBJETIVOS}

El objetivo fundamental de este trabajo es demostrar por qué y de qué manera el periodismo político puede considerarse periodismo especializado; para ello, realizaremos en primer lugar un breve repaso del estado de la cuestión, recordando los aspectos fundamentales que la investigación suele atribuir al periodismo especializado, y pasaremos después a comprobar en qué medida tales rasgos se cumplen o no en la especialización política; nuestra aportación final será vincular esa especialización a los procesos concretos de producción de la información, de tal manera que es la praxis profesional la que "mediatiza" esta especialización periodística.

La bibliografía española sobre periodismo ofrece un ingente corpus de publicaciones referidas al periodismo especializado, entre las que destacan, tras los trabajos iniciales de Orive y Fagoaga (1974), las aportaciones de Fernández del Moral (1983), Borrat (1993), Quesada (1995, 1998, 2009, 2012) y Esteve (2004, 2010). Sin embargo, el análisis conjunto de esta bibliografía, junto a algunas referencias de otros países, ofrece un panorama poco definido y en ocasiones contradictorio (Gallego, 2003; Meneses, 2007), porque se confunden sistemáticamente diversos planos de reflexión teórica, de manera que el concepto de "periodismo especializado" se maneja de forma tan genérica que pierde funcionalidad. Tal y como ha señalado Marchetti (2002: 
24): "la misma expresión de periodismo especializado no tiene mucho sentido si se emplea de manera demasiado general" (traducción propia).

Efectivamente, la especialización es un rasgo que puede observarse en todos los elementos del acto informativo o solo en alguno de ellos; hablar de "periodismo especializado" es en realidad una generalización que encubre diferentes elementos presentes en toda noticia; podemos, pues, tener periodistas especializados (que dominan con nivel de experto cierta esfera o área informativa), textos periodísticos especializados (que presentan los contenidos objeto de información con un alto nivel de profundización, rigor, y calidad informativa), publicaciones periodísticas especializadas (que conjugan rasgos de especialización temática y de autoría en sus textos), e incluso audiencias periodísticas especializadas (que poseen el bagaje informativo necesario para interpretar los textos elaborados con un nivel considerable de profundización y rigor).

Con este panorama bibliográfico como fondo explicativo, en este trabajo abordaremos cómo se manifiesta la especialización en periodismo político, atendiendo a la consideración de la producción periodística y las rutinas profesionales. Para ello, como punto de partida se elaboró una matriz de rasgos atribuidos por los diferentes autores al concepto de "periodismo especializado", buscando cuáles de ellos eran los más repetidos; posteriormente se analizó la relevancia de cada rasgo y su posibilidad de aplicación a todas las especialidades. Los rasgos más frecuentemente aducidos por las propuestas teóricas fueron: la especificidad temática, el enfoque en profundidad, la metodología de investigación, el recurso a fuentes expertas, la necesidad de formación complementaria a la propiamente periodística, la orientación a audiencias segmentadas, el uso de géneros textuales concretos y la adecuación lingüística. Los revisamos brevemente a continuación.

\section{LAS VARIABLES DEFINITORIAS DEL PERIODISMO ESPECIALIZADO}

En trabajos anteriores (Enguix, 2014, 2015) hemos esbozado una revisión de la bibliografía sobre periodismo especializado, poniendo de manifiesto la multiplicidad de rasgos y variables definitorios propuestos por los diferentes autores. Algunos de estos trabajos se elaboran a partir de encuestas a profesionales (Orive y Fagoaga, 1974; Fernández del Moral, 1983, 2004; Ramírez de la Piscina, 1999), mientras otros responden a la problemática del diseño de planes formativos de periodismo (Gutiérrez, 2009), a la reflexión teórica que busca delimitar parcelas dentro de una especialización que se asume como previa (Fontcuberta, 1993, 1997; Muñoz Torres, 1997; Quesada, 1998; Seijas, 2003; Mercado, 2011), o bien la proponen como evolución necesaria de la profesión periodística (Fernández Obregón, 1998; Túñez, 1999; Mcllwaine, Tanner y Green, 2001; Marchetti, 2002, 2005; Esteve, 2004; Meneses, 2007; Sor- 
many, 2011). Raras veces, sin embargo, estos textos se apoyan en muestras de datos amplias procedentes de la realidad informativa actual o en corpus acotados de textos, periodistas o medios.

Teniendo como horizonte su aplicación al periodismo político, repasamos a continuación ese estado de la cuestión, a fin de esclarecer si alguno de los rasgos propuestos puede ser considerado realmente definitorio del periodismo especializado y, por tanto, aplicarse a todas las especializaciones.

\subsection{Especificidad/coherencia temática}

Existe un alto grado de coincidencia en la idea de que el periodismo especializado se identifica por su especificidad/coherencia temática. Ante la multiplicidad de rasgos característicos manejados por los diferentes autores, con frecuencia contradictorios o inaplicables a todas las especialidades (Gallego, 2003; Meneses, 2007), el criterio temático se impone como una constante que permite identificar la especialización. Si bien algunos autores señalan explícitamente que esa coherencia temática no es rasgo suficiente (Quesada 1998; Túñez, 1999; Gutiérrez, 2009) pues, evidentemente, de casi cualquier texto puede decirse que aborda un tema específico, es habitual insistir en la especialización como un rasgo aplicado exclusivamente a los contenidos informativos: "No son los medios los que especializan sino los contenidos" (Fontcuberta, 1993: 53).

En esta especificidad temática del periodismo especializado se propone a veces la existencia de diferentes grados. Por ejemplo, Esteve (2010: 12) sugiere un primer nivel, que correspondería a las noticias de las secciones temáticas de los medios generalistas (lo que, en el ámbito que nos preocupa, podríamos identificar con cualquier noticia publicada en la sección de política de un diario generalista o en un informativo radiofónico); un segundo nivel lo constituirían los suplementos temáticos, ("Babelia" en El País, o "Motor" y "Salud" en El Mundo; también los cuadernillos monográficos que la prensa escrita suele dedicar a cada convocatoria electoral); y un tercer nivel sería el de medios especializados (por ejemplo, un magacín como Beerdergerg, que se autodefine como "La revista de política que nadie había pedido").

\subsection{Enfoque en profundidad y metodología de investigación}

La bibliografía coincide en señalar que el periodismo especializado exigiría un enfoque diferente al del generalista, que suele nombrarse como un tratamiento "en profundidad", y que no se limita a referir los hechos de actualidad, sino que los completa ofreciendo un análisis de las causas que hay detrás de los propios hechos, y una interpretación de los mismos (Esteve, 2010: 14). 
Según Quesada (2012: 13), la profundidad referida debe comprenderse por contraste: mientras el periodismo generalista busca dar respuestas concisas, claras y precisas al qué, quién, cuándo y dónde de cada hecho informativo, el periodismo especializado se preguntaría principalmente por el por qué y, en menor medida, cómo ha sucedido un hecho informativo, abordando también sus consecuencias. Curiosamente, Fernández del Moral y Esteve (1993: 180) recurren a las mismas categorías para señalar una descripción diferente, que pone énfasis en el qué: "la Información Periodística Especializada tiene como objetivo fundamental de su campo epistemológico el estudio del contenido informativo".

Sin embargo, ambas propuestas suponen separar las típicas $6 W$ con las que se ha teorizado desde siempre la naturaleza del periodismo en general, sin especialización. De ahí que en ocasiones, al describir el periodismo especializado como el ideal que debería sustituir al periodismo generalista surja la impresión de que, en realidad, lo que se caracteriza como periodismo especializado es, simplemente, el periodismo de calidad. Hasta el punto de que si radicalizamos esta visión normativizadora de lo que debería ser el periodismo especializado desde planteamientos académicos llegaríamos a pensar que el periodismo especializado de baja calidad es periodismo generalista, y que inversamente el periodismo generalista de calidad es periodismo especializado.

Del enfoque riguroso y en profundidad, así como del recurso a fuentes expertas, suele derivarse la exigencia de una metodología propia del periodismo de investigación (Quesada, 1995, 1998, 2004, 2012; Túñez, 1999). Se asume como idea de base que el periodismo generalista no satisface la demanda de un determinado público que desea obtener elementos de un acontecimiento que le permitan comprender mejor no sólo el hecho concreto, sino también su conexión con otros hechos y, al fin, con la propia sociedad (Quesada, 2012: 13). Entre las causas de estas carencias se suele mencionar la organización profesional/empresarial de los diarios, y entre sus consecuencias, la pérdida de eficacia comunicativa para explicar los hechos que conforman la realidad social. Y es precisamente el recurso a una metodología que evite estos riesgos lo que conduciría al periodismo especializado; dicha metodología, que constituiría el rasgo definitorio del periodismo especializado, sería la propia del periodismo de investigación (Quesada, 1998: 82; 1995: 80).

Pero si comparten la misma metodología, la cuestión que surge es la diferencia entre el periodismo especializado y el periodismo de investigación. El rasgo diferenciador entre ambos sería el elemento de actualidad que caracteriza al primero, frente a la oportunidad periodística del segundo; además, un rasgo identificativo del periodismo de investigación sería su preferencia por asuntos de difícil difusión cuyos protagonistas, por alguna razón, prefieren mantener ocultos. 


\subsection{El recurso a fuentes expertas y la formación de periodistas expertos}

Vinculada a la necesidad de ofrecer "una interpretación del mundo lo más acabada posible" (Orive y Fagoaga, 1974), la mayoría de los investigadores coinciden en señalar que el periodismo especializado supone una relación especial con fuentes expertas. Quesada (2009: 149) indica que en el modelo generalista es el periodista quien busca a la fuente experta (una fuente -apunta- con la que tiene poco trato y que por lo general lo "tiene en poca consideración"), mientras que cuando es la fuente quien busca a un periodista, se dirige siempre a profesionales especializados, a los que sí tendría por interlocutores válidos. Este dominio de los temas por parte de sujetos expertos plantea el problema de la autoría, es decir, quién firma los textos periodísticos especializados: mientras autores como Borrat (1993: 83) señalan explícitamente la posibilidad de que los textos del periodismo especializado no estén firmados por periodistas, otros como Elías (1999: 2), apuntan la idea de Fernández del Moral que señala a los antiguos "colaboradores" de prensa como los antecedentes directos del periodista especializado.

Desde nuestro punto de vista, sin embargo, es obvio que no todos los autores que publican textos en medios impresos (pensemos por ejemplo en los textos de economía que publican Paul Krugman o José Carlos Díez en El País) son por ello periodistas. Por el contrario, ceder la autoría directamente a las fuentes expertas supone interrumpir la tarea de mediación que define la profesión periodística. Esteve (2010: 9) señala precisamente que es el periodista quien funciona como interlocutor entre fuentes expertas y audiencias no expertas, para convertir los contenidos especializados en contenidos periodísticos o, en otras palabras, "hacer de cada especialidad algo comunicable" (Fernández del Moral y Esteve, 1993: 11). Probablemente en este punto resulta pertinente la diferenciación entre publicaciones de prensa diaria y publicaciones de prensa especializada; el periodista que firma un texto sobre temas de salud (Ana Macpherson en La Vanguardia, Cristina G. Lucio en El Mundo, Emilio de Benito o Ana G. Sevillano en El País) no necesita ser médico para realizar un trabajo de calidad, del mismo modo que el médico que escribe textos divulgativos para revistas especializadas no necesita ser periodista, por más que ambos deberán realizar un ejercicio de ajuste para sus respectivos destinatarios, y desarrollarán habilidades y conocimientos a partir de esa actividad.

Tal vez como respuesta a esta confluencia de saberes y habilidades, algunos trabajos sobre cómo deben ser los planes de estudio de Periodismo consideran que el periodismo especializado lo desarrolla necesariamente un periodista experto que tiene además una formación específica en su campo de saber ${ }^{1}$, rechazando explícitamente

\footnotetext{
1 En este sentido, Elías (1999) ha señalado que la experiencia intensa en cierta sección temática no determina periodistas especializados sino periodistas acostumbrados, indicando que el rasgo diferenciador entre unos
} 
la idea de que la autoformación, la experiencia y la veteranía puedan bastar. Creemos que cada ámbito temático determinará qué tipo de conocimientos necesita el periodista (contenidos, fuentes, actualidad, metodologías, grupos de interés) y si tales conocimientos dependen o no de estudios reglados concretos (Mcllwaine, Tanner y Green, 2001; Mercado, 2011).

\subsection{Audiencias segmentadas}

Otro lugar común en la bibliografía afirma que el periodismo especializado se desarrolla sobre todo como respuesta a la consolidación de audiencias selectivas y segmentadas, especialmente las propias de la era digital. Sin embargo, otros autores (Martínez Albertos, 1974; Borrat, 1993; Esteve, 2004, 2010) excluyen explícitamente este rasgo, oponiendo el periodismo especializado de los medios generalistas a la prensa especializada temáticamente, e insistiendo en que el periodismo especializado se dirige a audiencias generalistas; como indica Esteve, la información especializada no necesita ningún tipo de adecuación (lingüística, explicativa, contextualizadora, es decir, periodística) cuando sus destinatarios ya son especialistas en el tema.

\subsection{Idoneidad lingüística y de género textual}

Por último, la bibliografía menciona también ciertos rasgos secundarios sobre los tipos de texto y los usos lingüísticos que pueden contribuir a la caracterización del periodismo especializado. Algunos autores hacen referencia a la idoneidad de ciertos géneros periodísticos concretos, como la noticia, la crónica o el reportaje.

Además, la bibliografía destaca que el periodismo especializado supone cierta adecuación del lenguaje para públicos generalistas, precisamente porque los temas tratados suelen exigir un dominio terminológico o conceptual no disponible para todo el público, un terreno en que la mediación periodística especializada se asemejaría a la traducción. Esta necesidad de adecuación lingüística forma parte de la labor periodística general, aunque cabe pensar que cuando los temas son especializados pueden suponer al profesional mayor esfuerzo explicativo.

\footnotetext{
y otros sería la formación específica en el tema. Sin embargo, esta pretensión no solo es poco realista sino que se enfrenta de nuevo a múltiples posibilidades de áreas y subespecialidades: ¿qué estudios en concreto de ciencia o medicina debería cursar un aspirante a periodista científico, o de salud? ¿Y el periodista de deportes? Hay especializaciones bien consolidadas (periodismo de viajes, gastronómico, de tecnología) donde no sólo es difícil elegir esa carrera añadida a la formación periodística básica, sino que dependen absolutamente del conocimiento cambiante de cierta actualidad profesional, tecnológica o cultural.
} 
Vemos, al fin, que los rasgos que la bibliografía ha ido proponiendo para definir el periodismo especializado no son aplicables a la totalidad de textos que se adscriben a esa definición. En parte porque se manejan criterios que son propuestos para tipos muy concretos de especialización. En parte porque se asume la idea latente de que hay una especialización "apropiada" (la que afecta al proceso de elaboración de las noticias y se apoya en fuentes científicas y expertas), frente a una especialización que no lo es tanto y cuyos objetivos son exclusivamente comerciales, por lo que se equipara a simple segmentación/selección. Tal y como hemos mostrado, resulta necesario tener en cuenta que la idea de especialización no ha de ser aplicable al concepto global de periodismo, sino a uno o varios de sus múltiples factores: los profesionales, los temas, los medios/soportes, y las audiencias.

Estas realidades, diferenciables en cada noticia, se subordinan irremediablemente a la praxis profesional, cuyos tiempos, rutinas y cadenas productivas condicionan especialmente la metodología de trabajo. No es posible, en fin, asumir clasificaciones tajantes respecto a "periodismo especializado" atribuyéndole rasgos constantes, y resulta necesario en cada caso precisar mayor nivel de detalle por referencia a los elementos citados. Aunque las publicaciones fundamentales sí señalan esta diversidad de factores simultáneos, no siempre la incorporan a la reflexión posterior; y menos aún clarifican cómo la rutina profesional del proceso de producción informativa condiciona irremediablemente la especialización.

\section{LA ESPECIALIZACIÓN EN PERIODISMO POLÍTICO}

Así pues, la aplicación concreta al periodismo político de los rasgos propuestos por la bibliografía para el periodismo especializado nos lleva a las siguientes conclusiones. En primer lugar, vemos que al teorizar sobre las diferencias entre periodismo especializado y generalista se suele asumir, como planteamiento evaluativo de base, cierta preferencia o juicio positivo del primero frente al segundo, y de unos ámbitos temáticos sobre otros. Quesada, por ejemplo, señala (2012: 12) que el periodismo generalista se asocia con "la superficialidad y la parcialidad", y que no ofrece al lector "el nivel de especialización que permita satisfacer sus necesidades de información" (1995: 76). Estas críticas, y las reticencias de la investigación teórica para reconocer las pautas productivas de la profesión como elemento definitorio de la especialización reflejan una atención especialmente centrada en el contenido de los textos, sin considerar las dimensiones relativas al saber especializado de periodistas y de audiencias, sobre el cual unos y otras interpretan las informaciones. Esta atención preferente al contenido suele tener como referencia, además, ámbitos muy concretos de especialización (periodismo científico, económico, cultural), de manera que se proponen como característicos ciertos rasgos que no podrían aplicarse a todas las espe- 
cializaciones. Como veremos a continuación, la pieza periodística publicada en el periódico del día puede ser considerada "generalista", por ir dirigida al lector habitual de prensa, pero reflejar a la vez un profundo conocimiento de la realidad política que sirve de fondo a la noticia en cuestión.

En segundo lugar, las reflexiones sobre especialización revelan en general cierto desconocimiento de las condiciones de trabajo y las peculiaridades de las empresas de medios de comunicación, pues con frecuencia se responsabiliza al profesional de aspectos en los que solo es competente quien decide la organización de la plantilla y los flujos de trabajo (Gallego, 2003; Meneses, 2007; Marchetti, 2005, 2008). A este respecto Ramírez de la Piscina (1999) señalaba, por ejemplo, que las empresas tienden a preferir la contratación de periodistas generalistas, situación que se ha agravado especialmente desde la crisis de 2008. La posibilidad de desarrollar metodologías periodísticas especializadas, de investigación, o más recientemente de periodismo de datos, está directamente condicionada por los sistemas de producción y organización laboral; si en los años 90 la bibliografía repetía casi como un mantra la necesidad de atender a audiencias específicas y segmentadas, sustituyendo al periodista generalista por profesionales especializados, la situación actual de los medios revela la recuperación del "periodista todoterreno" (Turner y Orange, 2013; Knightley, 2013), con formación y habilidades suficientes para abordar diferentes áreas informativas y/o en diferentes soportes (audiovisual, impreso, digital, multimedia).

Son varios los autores que incluyen explícitamente el periodismo político como modalidad de periodismo especializado (Orive y Fagoaga, 1974; Muñoz Torres, 1977; Fontcuberta, 1993; Elías, 1999; Marchetti, 2002, 2005; Esteve, 2004; Torró, 2013; Carrasco, 2013; Rafter, 2013; Turner y Orange, 2013). En este apartado argumentamos la especial naturaleza de tal especialización, que necesita apoyarse en la especificidad de los procesos de producción informativa. Lo que ocurre es que mientras, por un lado, el periodismo político constituye un área de especialización, por otro da cobertura a un área temática que calificamos como prototípica, es decir, inseparable del propio concepto de periodismo; dicho en otras palabras, cabría afirmar que el periodismo político es el periodismo por excelencia.

\subsection{La importancia del periodismo político}

Al describir el periodismo político como prototípico pretendemos dar cuenta de varios factores, derivados del hecho de que todas las definiciones le confieren naturaleza de actor político en las sociedades de las que forma parte. No es de extrañar, por tanto, que las informaciones políticas constituyan el núcleo informativo fundamental de los rotativos de información diaria, tanto en cantidad de informaciones como en importancia concedida a las mismas; o que la información política impregne los in- 
formativos de las televisiones y radios generalistas. Se suma a ello la relevancia histórica de la información política en la aparición y desarrollo de la prensa (Gifreu, 1996; Gómez Mompart, 1992; Tresseras, 1994).

Además, los periodistas políticos son percibidos por la profesión como un grupo especial debido a sus relaciones con los partidos y gobiernos, lo que explica que con frecuencia se les dé participación -como expertos- en espacios de opinión (tertulias de radio o televisión en medios ajenos al propio, papel destacado de sus perfiles en blogs o redes sociales, etc.). Por ejemplo, Charon (1994: 38) señalaba para el periodismo francés la existencia de un grupo en torno al centenar de periodistas políticos, cuyo prestigio derivaría del hecho de que sus decisiones y opciones informativas tienen un efecto dominó sobre el resto de medios: "son ellos quienes interpretan los acontecimientos, quienes deciden a cuál de ellos se dará protagonismo, y quienes organizan la cobertura de noticias" (traducción propia). Indica el mismo autor (también Legavre, 2005) que la mayor parte de los directores y editores de periódicos proceden de la especialización política. Igualmente en el ámbito español, Rodríguez y Santillán (2012) comprueban la importancia de esta especialización en el conjunto del ecosistema mediático. Una importancia que se ratifica, además, con el análisis de las noticias de portada de los principales rotativos españoles (Enguix, 2013).

Efectivamente, el análisis de las noticias de portada de los diarios El País, El Mundo y La Vanguardia a lo largo de todo un año (Enguix, 2013) evidencia el predominio de las noticias de tema político, con un reparto de subáreas donde los temas de política estricta son mayoría, con un porcentaje global del $54,4 \%$, seguidas en orden decreciente de presencia por las de temática social $(44 \%)$, política económica $(38,4 \%)$, la internacional $(35,5 \%)$, economía $(26 \%)$, cultura $(28,4 \%)$, deportes $(23,7)$, política internacional $(20,7 \%)$, terrorismo $(10,4 \%)$, políticas socioculturales $(11,8 \%)$ y política y tribunales $(5,45 \%)$.

Sin perder de vista esta presencia destacada del periodismo político en el ecosistema informativo (en temas, en profesionales, en publicaciones, en el propio debate social), pasamos a revisar los rasgos propios de este ámbito de especialización, siguiendo como hilo argumental las características de la especialización que hemos presentado en el apartado previo, pero alterándolo ocasionalmente cuando sea necesario introducir los elementos más definitorios de este campo.

\subsection{Identidad temática (y funcional) del periodismo político}

Resulta obvio que el periodismo político se corresponde con un cuerpo específico de temas y actores (Enguix, 2013, 2015) que le dan entidad propia: elecciones, acciones de gobiernos, acciones de los partidos políticos, reacciones ciudadanas al hecho 
político, acciones de los poderes legislativo y judicial... En definitiva, lo que las definiciones clásicas de política vinculan con la búsqueda y defensa del bien común. Creemos que de esta temática derivan dos niveles de caracterización del periodismo político.

Así, cuando se analiza esta especialización del periodismo atendiendo a sus aspectos más externos, nos planteamos su papel en el ámbito global de la comunicación política de una sociedad y su función en el propio sistema político. Teniendo en cuenta la realidad profesional cotidiana vemos que el periodismo político define un lado concreto de lo que a veces se concibe en términos de cierta "trinchera comunicativa", que lo enfrenta tanto a la comunicación política institucional como al marketing político de los partidos y las instancias gubernamentales. Esta posición, además, tiene una doble naturaleza, ya que es a la vez una posición comunicadora, que ejerce mediación entre los actores políticos institucionales y la ciudadanía, y una posición políti$c a$, que puede condicionar el debate político mediante recursos bien conocidos, como el establecimiento de la agenda, el encuadre o la preactivación.

Si atendemos a una dimensión más interna y nos planteamos cuáles son las esferas temáticas específicas de las que habla el periodismo político, cabe concluir que este se despliega en dos dimensiones informativas fundamentales: por un lado la referida al "juego político" entre partidos, instituciones, y sus representantes; y por otro lado la que incluye todas las esferas de la acción política de una sociedad (las políticas públicas). En la primera dimensión, que podemos considerar como de política estricta, las noticias son generadas básicamente desde tres ámbitos, que son:

- La acción política de gobiernos y parlamentos.

- La acción política de los partidos (especialmente los procesos electorales).

- Los acontecimientos políticos extraordinarios.

La cobertura institucional es, sin duda, el mayor campo de despliegue de los temas del periodismo político. A diferencia de lo que ocurre en otros ámbitos de especialización, el periodista político debe atender tanto al nivel estricto de los hechos políticos como al nivel de la comunicación política emanada de las instancias de poder y la relación comunicativa que se establece con ellas (es decir, la oposición entre media management y la information management, Mazzoleni, 1998: 60). Mientras en la gestión mediática el profesional puede obtener gran colaboración de los políticos y sus asesores (que buscan, en última instancia, la máxima visibilidad mediática), la gestión informativa estricta puede suponer un trabajo más competitivo que colaborativo.

En la segunda dimensión informativa, la de los asuntos públicos referidos al bien común, los temas fundamentales identificados para el periodismo político son (En- 
guix, 2015): política económica, política internacional, política y tribunales, política social (especialmente sanidad), política educativa y cultural y, finalmente, política y terrorismo.

\subsection{Formación y conocimiento experto del periodista político}

Respecto a la necesidad de un saber experto, la formación de todo periodista debe incluir una base teórica de conocimientos cuyos contenidos mínimos incluirán dos grandes esferas de contenidos: por un lado, temas sobre el papel del periodismo político en las sociedades democráticas y, por otro, temas sobre metodología y habilidades profesionales (Enguix, 2014).

En consonancia con esta formación básica, cabría pensar que a todo periodista se le supone capacidad profesional para la cobertura de la información política, por lo que la bibliografía no suele reclamar la formación reglada añadida que sí se propone, por ejemplo, para la información científica, económica o medioambiental. Sin embargo, el panorama actual de grados europeos de la universidad española ofrece un alto grado de divergencia entre las diferentes universidades, y mientras hay títulos con varias asignaturas específicas sobre periodismo político, historia e instituciones, ciencias políticas, y/o sociología, existen otros currículos que no tratan ninguno de estos temas durante toda la carrera.

Por lo que respecta a la opinión de los profesionales, en una encuesta realizada a periodistas políticos ${ }^{2}$ (Enguix, 2013), se les plantearon cuestiones relativas a la necesidad de una formación específica sobre esta especialidad. El gráfico muestra los resultados de las preguntas relativas a la formación, agrupados en tres valores (1 máxima disconformidad, 5 máxima conformidad):

2 El cuestionario se envió a directores, subdirectores, redactores jefes, jefes de sección, redactores y directores de delegaciones, de los diarios La Vanguardia, El País, Levante-EMV, Las Provincias, Diari ARA, El Mundo, El Periódico de Catalunya, La Razón, ABC, La Verdad de Murcia y El Heraldo de Aragón. Se entrevistó también a dos profesionales del semanario El Temps dedicados a la información política y al director de Valencia Plaza, Cruz Sierra, por su larga experiencia como periodista político. De los 46 contactados, contestaron a la encuesta 45: seis directores de medios, cinco subdirectores, un director adjunto, nueve jefes de sección, diecinueve redactores, $y$ cinco redactores jefes. 
Imagen 1. Opinión de los profesionales sobre la formación universitaria en periodismo político (porcentaje de las respuestas)

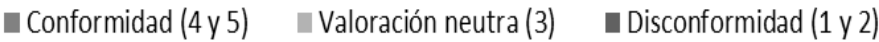

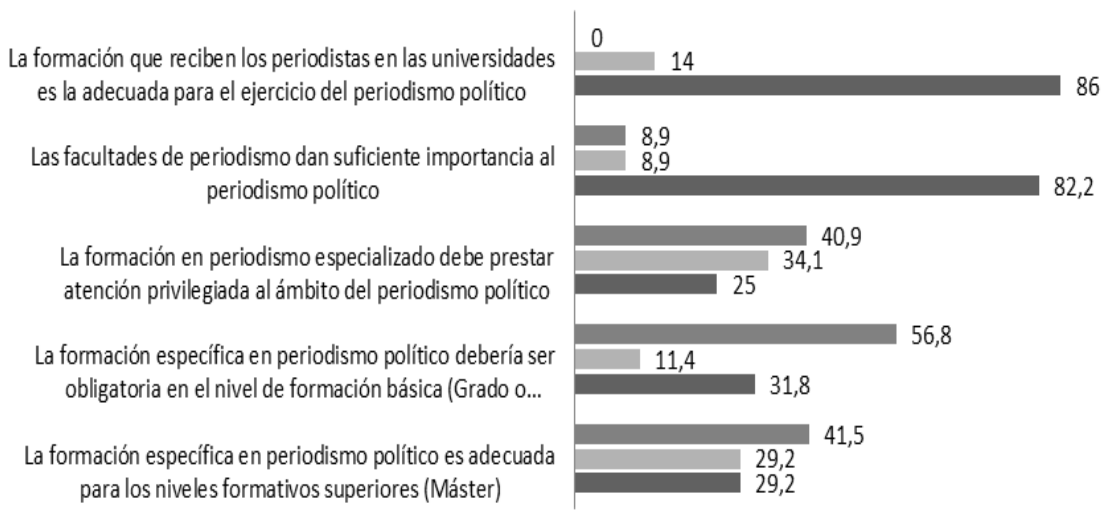

Fuente: Elaboración propia.

Como puede verse en el gráfico, hay amplia coincidencia ( $86 \%$ de respuestas) en que la formación universitaria en periodismo político resulta insuficiente, y que las facultades no dan la necesaria importancia a esta especialización (82,2\% de conformidad); un 56,8\% de los informantes considera que es una formación propia del grado y un $41,5 \%$ piensa que es una formación más adecuada para el nivel de máster. Los profesionales, pues, no parecen apostar por una formación complementaria específica (como sería, por ejemplo, que el periodista especializado en salud estudiara cursos de medicina), sino que consideran que debe integrarse en la propia formación como periodistas. Algunas observaciones recogidas en la mencionada encuesta señalan esta idea, o insisten en la adquisición de un saber ajeno a las aulas:

- "Los estudiantes de periodismo suelen creer que hacer periodismo político es sinónimo de hacer activismo ideológico. La primera función de las facultades tendría que ser quitarles esta idea de la cabeza" (Informante 8, Redactor).

- "La formación específica en periodismo político es muy útil para muchos órdenes de la vida. Es un apartado de la profesión que debería tener mucha mayor atención en las facultades" (Informante 16, Jefe de Sección). 


\subsection{Las fuentes en el periodismo político}

Efectivamente, junto al conocimiento teórico sobre el funcionamiento de instituciones políticas, existe otro tipo de conocimiento que no puede adquirirse en lecturas y universidades sino, precisamente, a partir de la praxis profesional, entrando en contacto directo con los representantes políticos de cada sociedad. Con anterioridad hemos valorado cómo varios autores remitían a las "fuentes expertas" como condición sine qua non para identificar el periodista/periodismo especializado. Creemos, justamente, que la relación del periodista político con las fuentes de información del área política define en gran parte la especialización.

La relación del periodista político con sus fuentes es distinta a la del periodista deportivo, científico, o de salud, etc., debido precisamente a la naturaleza política de las informaciones. La praxis profesional y la rutina productiva en un medio de comunicación, especialmente en un periódico, confirma que lograr la confidencialidad de una fuente es un objetivo difícil, lento y que supone para el informador muchos días, semanas, meses, a veces incluso años, lo que confiere a la relación cierto matiz de personalización. El periodista que desarrolla una buena labor en el área política de un medio debe necesariamente haber adquirido una buena relación con las mejores fuentes de información de esa misma área, lo que determina, a nuestro juicio, la especialización de ese profesional, aspecto este que no suele reflejar la bibliografía sobre especialización periodística y que no se da en otros posibles ámbitos de especialización.

\subsection{Metodología en la producción de noticias y tratamiento en profundidad}

Como hemos visto, gran parte de la bibliografía coincide en señalar que el periodismo especializado exige abordar la actualidad informativa con una metodología propia del periodismo de investigación, adoptando un enfoque en profundidad para los textos. Según este punto de vista, el periodista político en sí mismo nunca sería un "periodista especializado" mientras no adoptara en su dinámica productiva esta metodología: ni el conocimiento del área informativa (funcionamiento de instituciones, reglamentos, etcétera), de las fuentes, de las rutinas políticas, del tiempo dedicado a esta área informativa, sería suficiente para la calificación de "especializado", ya en su función ya en el periodismo que desarrolla.

Según esta línea de reflexión que hemos descrito, caracterizada por cierta intención normativizadora, un redactor del área de política de un periódico jamás podría ser considerado periodista especializado si no asumiera, en algún momento de su producción informativa, las condiciones y metodologías productivas señaladas: la metodología del periodismo de investigación, y la profundidad y contextualización de 
los hechos informativos, principalmente. Se parte, a nuestro juicio de manera errónea, de que el periodismo generalista limita su labor a explicar el qué, quién, cuándo y el dónde, lo que excluiría la producción de géneros informativos e interpretativos como el reportaje (no el reportaje de investigación, cuyas características están bien diferenciadas), la crónica informativa (género notable en el área de información política), o incluso la noticia extensa. De alguna manera, se equipara el periodismo generalista con la producción de textos del género noticia, género dinámico del que abundan los ejemplos en prensa escrita. Hay que señalar que la noticia extensa, género que en ocasiones se confunde erróneamente con la crónica, y cuya razón de ser es, precisamente, explicar el cómo y el porqué de un hecho, se ha convertido en un género fundamental en la prensa escrita, sobre todo desde la eclosión del soporte digital. Por otro lado, al condicionar la especialización a la metodología se infravalora el tiempo, la exigencia, el conocimiento y el trato con las fuentes que supone la actividad informativa.

Desde nuestro punto de vista, la exigencia de una metodología de investigación no puede mantenerse para el periodismo especializado en política, orientado a dar un tratamiento en profundidad de los temas que conforman la actualidad de un gobierno y unas instituciones. Cuando un Presidente de gobierno nombra sustituto pocas horas después de la dimisión de un ministro o celebra reuniones con unos y no otros representantes autónómicos, cuando un consejero anuncia inversiones estatales o cambios impositivos en su comunidad, o cuando cierto gobernante extranjero visita el país y se entrevista con empresarios, asistimos a actos políticos que necesitan publicación inmediata por parte de los medios en sus canales impresos/audiovisuales y digitales (páginas webs, redes...) y cuya interpretación contextualizada no se apoya en una formación académica concreta, sino en un saber profesional que exige conocer, por ejemplo, cómo son las personalidades, trayectorias y relaciones de los miembros de los partidos y los gobiernos, o cuáles pueden ser las consecuencias de una crisis de gobierno en cierto momento concreto, o entender el funcionamiento de las relaciones internacionales, así como conocer la historia política que construyen estos representantes (las relaciones entre partidos y dentro de cada partido), asistiendo regularmente a las sesiones parlamentarias y las ruedas de prensa.

Se trata, en definitiva, de un saber acumulado que se nutre, precisamente, de la propia actualidad política. Y ese mismo saber profesional acumulado, que permite al periodista un conocimiento de hechos, situaciones y personas, se completa además con el saber metodológico periodístico en el manejo de fuentes y en la documentación necesaria para elaborar los textos, siempre ajustándose a los ritmos y tempos derivados de cada medio concreto. Los conocimientos teóricos y académicos sobre instituciones o sobre sistemas políticos, que deben ser proporcionados por las titulaciones universitarias de periodismo, facilitan una especie de red conceptual de posibi- 
lidades abstractas que solo se vuelve operativa desde el punto de vista informativo cuando esas categorías se concretan en la política real de una sociedad o un territorio, es decir, con unos nombres propios concretos y unas relaciones y unas políticas determinadas.

Esta especialización profesional se refleja en la cobertura que realizan los grandes diarios en las campañas electorales, acontecimiento político por excelencia. Por ejemplo, un análisis del seguimiento de las elecciones europeas de 2014 en las versiones impresas de El País, El Mundo, La Vanguardia y ABC muestra, entre el 27 de abril y el 27 de mayo de $2014^{3}$, estos datos:

- El País: encontramos 226 piezas periodísticas firmadas, de las cuales 210 son informativas (un 92,9\%) y el resto son artículos o columnas de opinión. En esos textos de información, los profesionales más frecuentes son: Carlos E. Cué, que firma un $13,8 \%$ de los textos informativos, Francesco Manetto (9\%), Fernando Garea (7,6\%), Joaquín Ferrandis (7,1\%), y Anabel Díez (6,2\%).

- El Mundo: 349 textos firmados, de los cuales 279 (un 79,9\%) son informativos. Luis Ángel Sanz firma un $11,8 \%$ de los textos informativos, seguido de Héctor Sanjuán (10\%), Carmen Remírez de Ganuza (9,1\%) y Javier García Gallego (9\%).

- La Vanguardia: 255 firmados, de los cuales 181 informativos (un 70,9\%). Beatriz Navarro firma un 9,9 de los textos informativos, pero también, como corresponsal de Bruselas, un 16,1\% de los textos de opinión ("Agenda de Bruselas"). Carmen del Riego, un 13,3\% de los textos informativos, Josep Gisbert un 10,5\%, e Iñaki Ellakuría un 9,9\%.

- $A B C$ : durante el mes analizado se publican 312 textos firmados, de los cuales 226 son textos informativos (un 72,4\%) y el resto de opinión. Mariano Calleja firma un $18,8 \%$ de los textos informativos, Paloma Cervilla el 10,1\%, y Gabriel Sanz el 7,9\%.

Así pues, la aplicación de los rasgos de especialización al periodismo político nos lleva a identificar como rasgos definitorios: su identidad temática, pero también funcional; su conocimiento experto doblemente anclado en el saber objetivo (formación reglada) y en la experiencia profesional acumulada; su especial relación con las fuentes; y también su metodología de trabajo (que no puede ajustarse en todos los casos al periodismo de investigación). Como consecuencia de esta caracterización, y a diferencia de otras especializaciones, resulta necesario introducir como rasgo caracterís-

\footnotetext{
${ }^{3}$ Las elecciones fueron el 25 de mayo, y la campaña electoral tuvo lugar del 9 al 24 de mayo. Para este análisis se ha trabajado con las versiones impresas de la Comunidad Valenciana de los cuatro periódicos mejor posicionados en el Estudio General de Medios del momento.
} 
tico un aspecto que no aparece en la bibliografía sobre especialización periodística y que se refiere a las rutinas profesionales.

\subsection{Las rutinas profesionales en el periodismo político}

Martínez-Nicolás y Humanes (2012: 52) señalan que la cultura profesional del periodismo se desarrolla en dos líneas básicas: la que se relaciona con los valores profesionales y éticos (el ethos periodístico), y la que se centra en los procesos concretos de producción y que suele englobarse en el rótulo de "rutinas profesionales".

Aunque profundizar en el primero de estos niveles excede los objetivos de este trabajo, la caracterización del periodismo político como especialización sí puede apoyase en la existencia de esa dimensión ética, ideológica, de innegable repercusión social, que sin embargo está ausente en otras especializaciones. Tales valores ideológicos no apuntan en realidad a una postura política concreta (el paralelismo político de Hallin y Mancini), sino que se refieren a la propia profesión, a la responsabilidad que surge por el valor de la prensa política en la sociedad y su función de control del poder; es decir, se trata de elementos incorporados por los profesionales en su propio concepto del ejercicio periodístico (Enguix, 2015: 109). Autores como Kovach y Rosenstiel (2001) o Deuze (2005) han enfatizado al respecto características como la búsqueda de la verdad, la lealtad básica hacia la ciudadanía, la independencia editorial y respecto a los protagonistas de la actualidad política, el ejercicio del control independiente del poder político, etc.

Por lo que se refiere al nivel de las rutinas profesionales del periodista político, referidas a la producción informativa, vienen condicionadas por múltiples factores que condicionan todo el proceso, desde las dinámicas que impone la actualidad política hasta el soporte en el que el periodista distribuye los contenidos (escrito impreso o digital, audiovisual). Destacamos a continuación algunos de los factores que condicionan directamente la labor profesional y que, aunque pueden darse en otros ámbitos de especialización, tienen en el área del periodismo político una identidad específica, sobre todo en lo referido al tratamiento de las fuentes y a la labor de auditoría de los poderes públicos.

\subsubsection{La agenda diaria}

El periodismo político da cobertura, principalmente, a las instituciones políticas y a los actores políticos, y también a aquellos actores no políticos cuya actividad puede modificar o alterar, con su movilización o acción, el propio ecosistema político (sindicatos, tribunales o colectivos sociales). En todos estos casos se establecen agendas de trabajo (debates, comparecencias, citaciones judiciales, etcétera) que obligan al informador a determinar su rutina de producción. La selección y jerarquización de las 
actividades previstas en agenda supone, en sí mismo, una de las labores claves previas a la selección aquellos hechos susceptibles de transformarse en noticia, y son, en lógica, parte del proceso de jerarquización informativa.

Obviamente, la configuración de la agenda está sometida a los recursos de producción del área política (pocos o muchos redactores disponibles) y a los hechos extraordinarios (dimisiones, pactos imprevistos, decisiones no programadas), que pueden alterar toda la agenda planificada con antelación. Asimismo, la intensidad de la agenda viene finalmente condicionada por el ámbito de cobertura del propio medio de comunicación: local, autonómico o nacional.

\subsubsection{Las rutinas de producción}

El trabajo del periodista político está sometido al sistema de producción propio del medio en el que desarrolla su función. En el caso de la prensa escrita, al sistema "industrial", a la apertura de páginas -generalmente a primera hora de la mañana- y al cierre de las ediciones -generalmente a primera hora de la madrugada-, condicionados por la impresión y la posterior distribución. En el caso de los medios digitales, las rutinas se han visto alteradas y se asemejan mucho a las que se desarrollan en los medios radiofónicos y audiovisuales.

En el caso de la prensa escrita, el espacio disponible, es decir, el tamaño que el periodista dispone en papel para divulgar su información, encorseta el relato del hecho noticiable: no es lo mismo redactar un "breve" informativo que un reportaje de 4.000 o 6.000 caracteres. En lógica, cuanto más espacio más riqueza habrá en la exposición escrita del hecho abordado. En los medios digitales este problema apenas existe, por cuanto el soporte posibilita un espacio infinito para ofrecer la versión de los hechos. En radio y televisión, la condición viene determinada por el tiempo disponible.

\subsubsection{La interacción con otros profesionales}

Las interdependencias que gestiona diariamente el periodista político para el desarrollo de su labor son múltiples, pues la función de mediación impone la comunicación constante con los representantes de las instituciones políticas, los gestores de la comunicación política (dircoms, asesores, jefes de prensa, etcétera), las fuentes, y otros profesionales.

A ello se suma que el periodista político suele ser consultado en diferentes ambientes y otros medios sobre todos aquellos hechos que condicionan el debate social. También va en aumento su función de referencia en las redes sociales, en las que interviene amplificando la versión digital de su producción, e interactuando con pro- 
fesionales, y/o fuentes, y/o audiencias; la participación en estas redes forma parte ya, también, de las rutinas de producción, como consecuencia de los cambios en los hábitos de consumo informativo por parte de las audiencias.

\subsubsection{La interacción con las fuentes}

Este es, posiblemente y desde nuestro punto de vista, el factor que más diferencia al periodista político de los profesionales del resto de áreas informativas. En primer lugar, según dijimos, porque se trata de fuentes que, en la mayoría de los casos, son parte del poder que distribuye los recursos públicos o son fuentes próximas a las primeras. Se trata, además, en muchos casos, de fuentes doblemente condicionadas: pertenecen a un partido político y pueden, al tiempo, ocupar un cargo público (es decir, deben fidelidad al partido y a la institución). La historia del periodismo cuenta con grandes hitos informativos logrados a partir del contacto con fuentes próximas al poder, y con acontecimientos que, como el caso Watergate, han llegado a modificar el ecosistema político de todo un país. No existe, en este sentido, ninguna otra área de especialización donde la tensión periodista-fuente sea tan intensa, tan condicionada, y con consecuencias tan notables para la propia sociedad y para la opinión pública.

Esto explica que la comunicación política, entendida como las acciones que se activan desde las instituciones para condicionar a los medios, a los periodistas y -siguiendo este razonamiento deductivo-, a la propia opinión pública, sea una de las disciplinas donde más recursos y medios se han invertido en las últimas décadas. No existe en ninguna otra área informativa un esfuerzo tan enorme por parte de los actores (culturales, deportivos o incluso económicos) para intentar moldear e incluso manipular el trabajo de los profesionales de la información.

\subsubsection{El conocimiento del área informativa}

Finalmente, el periodista político es, a diferencia de otros redactores de otras áreas, un profesional en permanente formación en ámbitos como el derecho constitucional, la teoría política, el derecho procesal y otras áreas de conocimiento fundamentales para el correcto trabajo. El propio reciclaje modifica y condiciona las rutinas profesionales pues, como en el caso de los procesos judiciales, obliga al periodista político a renovar sus conocimientos para poder observar e interpretar correctamente hechos, en algunos casos, de enorme alcance. Y es este, finalmente, un factor clave para diferenciar al buen profesional, capaz de enlazar hechos y lecturas de la realidad, y ofrecer hipótesis y prospectivas (caso de procesos electorales, por ejemplo) sobre la evolución de las relaciones de poder en un determinado espacio geográfico y político. 


\subsection{Audiencias especializadas}

Con este aspecto retomamos de nuevo el listado de rasgos que se proponían para la especialización periodística. Si el periodismo se define como actor político y el periodismo político es el periodismo por excelencia, ¿qué nivel de formación/información política debe suponerse al lector medio de los diarios? La respuesta a esta pregunta depende sin duda del tipo de sociedad en que nos hallemos y del grado general de compromiso cívico de los lectores de prensa. En general, cabría suponer un nivel mayor de especialización informativa al lector de, por ejemplo, TintaLibre y Cuadernos, las revistas de los diarios digitales Infolibre y eldiario.es, que a los lectores medios de tales diarios.

\subsection{Los géneros del periodismo político}

En el caso del periodismo político puede afirmarse que todos los géneros son adecuados. El estudio ya mencionado (Enguix, 2013) de las portadas de El País, La Vanguardia y El Mundo durante todo el año 2011 destaca el predominio del género Noticia, con un $85,7 \%$ del total de textos políticos de las portadas, si bien cabe pensar que la propia ubicación en portada condiciona de algún modo este resultado.

Imagen 2. Distribución de géneros en las noticias políticas de portada en los principales diarios españoles durante el año 2011

Predominio absoluto del género Noticia para la información política de portada de todo un año

\#EL MUNDO IL VANGUARDIA —EL PAÍS

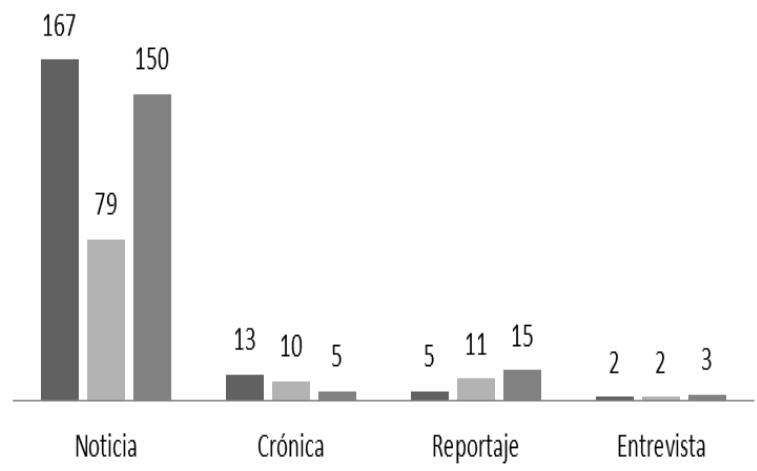

Fuente: Elaboración propia. 
Si no limitamos el análisis a las portadas, por ejemplo en lo referente a la cobertura del proceso electoral del Parlamento Europeo en 2014 en El País, El Mundo, La Vanguardia y $A B C$, vemos que también predomina el género noticia en las páginas interiores de los diarios. Entre los textos informativos dedicados a las elecciones, las noticias suman un $57,4 \%$ del total de la cobertura electoral en los cuatro rotativos, y las crónicas/reportajes un $17 \%$.

\section{Imagen 3. Distribución de géneros en la cobertura informativa de las elecciones europeas de 2014, en los principales diarios españoles \\ Distribución por géneros de los textos informativos en la cobertura de las elecciones europeas 2014}

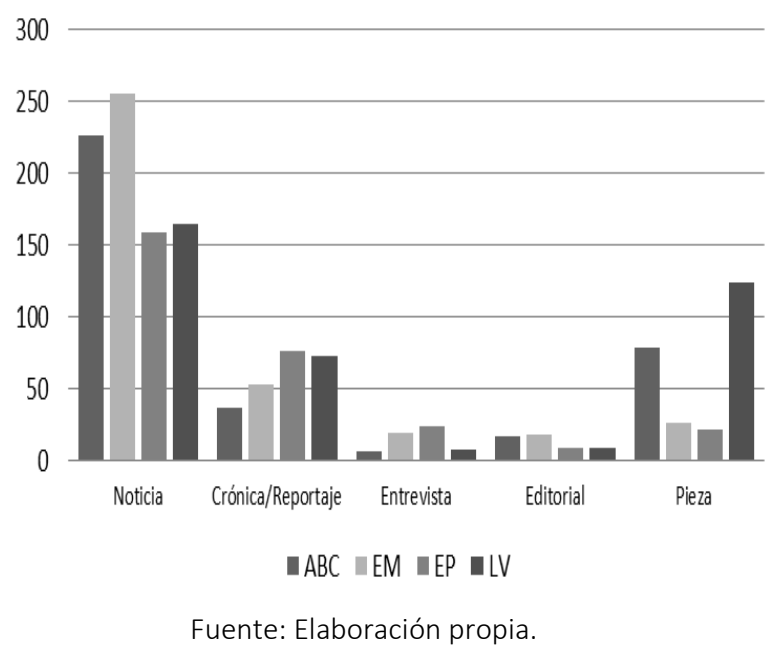

\section{CONCLUSIONES}

La revisión de la bibliografía sobre periodismo especializado pone de relieve la necesidad de matizar el concepto, ya que la especialización puede referirse conjunta o separadamente a diversos elementos: el profesional que conoce detalladamente cierto ámbito informativo, el tratamiento en profundidad de los contenidos, las audiencias determinadas por ciertos intereses selectivos, o los propios medios que acotan como objeto cierta esfera de conocimiento (magacines, canales temáticos). Hemos revisado las publicaciones fundamentales sobre el tema para ver cómo esta multiplicidad de niveles explica que a veces se hayan propuesto como rasgos definitorios del periodismo especializado características que, o bien solo pueden aplicarse a espe- 
cializaciones concretas o, por el contrario, pueden formularse también para todo el periodismo generalista de calidad.

Creemos que el periodismo político sí puede considerarse un tipo de periodismo especializado si aceptamos como tal aquellos textos que, incluidos en los medios generalistas dirigidos al gran público, tratan temas que pertenecen a una esfera acotada de conocimiento y completan la simple presentación de los hechos con un tratamiento explicativo e interpretativo; un tratamiento que puede apoyarse en el uso de fuentes expertas y en la metodología de investigación, pero también en el conocimiento experto acumulado del propio periodista.

Los rasgos definitorios de la especialización política derivan de la propia cultura profesional, tanto los referidos al valor social del periodismo en su faceta de actor político, como los que definen las rutinas de producción informativa; proceden de la elevada exigencia en el conocimiento del área (funcionamiento de las instituciones, principalmente), de la naturaleza política de las informaciones manejadas, y muy especialmente, de la compleja relación que debe establecer el periodista político con las fuentes. Es decir, son rasgos directamente vinculados con los valores profesionales y la función social del periodismo político, que condicionan las rutinas de información política en factores concretos como la agenda diaria, las rutinas cotidianas de producción, la interacción con otros profesionales y la relación con las fuentes.

En sentido contrario debería entenderse que ningún periodista puede alcanzar un nivel de calidad informativa diaria en el área de información política de un medio de comunicación, especialmente escrito, si no posee un elevado conocimiento de la materia con la que se trabaja y un estrecho contacto con las fuentes políticas. Lo que obliga a deducir que es la propia dinámica productiva la que constituye por sí misma un ejercicio de "profundidad" informativa y permite, en los géneros noticia o crónica principalmente, tratar el porqué de un hecho informativo político.

\section{BibLIOGRAFÍA}

BORRAT, H. (1993): "Hacia una teoría de la especialización periodística”, Anàlisi, no 15, pp. 79-84.

CAMACHO, I. (coord.) (2010): La especialización en Periodismo. Formarse para informar. SeviIla / Zamora: Comunicación Social.

CARRASCO, R. (2013): “Introducción a las áreas del periodismo", en Cebrián, B. y Mirón, L. (coords.): Áreas del periodismo. Zamora: Comunicación Social, pp. 13-22.

CHARON, J. M. (1994): "The fragmentation of journalism", Réseaux, vol. 2, no 1, pp. 37-53. DOI: http://dx.doi.org/10.3406/reso.1994.3259. 
DEUZE, M. (2005): "What is journalism? Professional identity and ideology of journalists reconsidered", Journalism, vol. 6, no 4, pp. 442-464. DOI: http://dx.doi.org/10.1177/1464884905056815.

ELÍAS, C. (1999): "Periodistas especializados y acostumbrados: la divulgación de la ciencia", Revista Latina de Comunicación Social, no 58. Disponible en http://goo.gl/nVVhB5. Consultado el 10 de julio de 2014.

ENGUIX OLIVER, S. (2013): El periodismo político en España. València: Universitat de València. Tesis doctoral. Disponible en http://roderic.uv.es/handle/10550/28017.

ENGUIX OLIVER, S. (2014): "La docencia de periodismo político: competencias específicas y actividades para su aprendizaje", V Trobades d'Innovació Educativa, Universitat de València, 29 y 30 de enero de 2014.

ENGUIX OLIVER, S. (2015): Periodismo político: fundamentos, práctica, perspectivas. Bellaterra / Castellón / València: UAB / UJI / UV.

ESTEVE RAMÍREZ, F. (2004): "Funciones socioculturales en el periodismo especializado", en VV.AA.: Actas VIII Congreso de la Sociedad Española de Periodística. Estudios de Periodística XI. Barcelona: Universitat Autònoma de Barcelona, pp. 205-220.

ESTEVE RAMÍREZ, F. (2010): "Fundamentos de la especialización periodística”, en Camacho, I. (coord.): La especialización en periodismo. Formarse para informar. Sevilla/Zamora: Comunicación Social, pp. 11-26.

ESTEVE RAMÍREZ, F. y FERNÁNDEZ DEL MORAL, J. (1999): Áreas de Especialización Periodística. Madrid: Fragua.

FERNÁNDEZ DEL MORAL, J. (1983): Modelos de comunicación científica para una información periodística especializada. Barcelona: Dossat.

FERNÁNDEZ DEL MORAL, J. (2004): “El periodismo especializado: un modelo sistémico para la difusión del conocimiento", en Fernández del Moral, J. (coord.): Periodismo especializado. Barcelona: Ariel, pp. 17-32.

FERNÁNDEZ DEL MORAL, J. y ESTEVE, F. (1993): Fundamentos de la Información Periodística Especializada. Madrid: Síntesis.

FERNÁNDEZ OBREGÓN, F. (1998): "Especialización, futuro del periodismo", Revista Latina de Comunicación Social, no 7. Disponible en http://goo.gl/oKZov. Consultado el 30 de junio de 2014.

FONTCUBERTA, M. de (1993): La noticia. Barcelona: Paidós.

FONTCUBERTA, M. de (1997): "Propuestas sistémicas para el análisis y producción de información periodística especializada", en Esteve, F. (coord.): Estudios sobre Información Periodística Especializada. Valencia: CEU San Pablo, pp. 17-23.

GALLEGO AYALA, J. (2003): Información de sociedad. Del suceso a la calidad de vida. Bellaterra: Universitat Autònoma de Barcelona. 
GIFREU, J. (1996): Estructura general de la comunicació pública. Barcelona: Pòrtic.

GÓMEZ CALDERÓN, B. (2010): “El análisis, un género interpretativo al servicio de la especialización periodística”, en Blanco, E. y Esteve, F. (eds.): Tendencias del periodismo especializado. Málaga: Universidad de Málaga, pp. 329-336.

GÓMEZ MOMPART, J. L. (1992): La gènesi de la premsa de masses a Catalunya (1902-1923). Barcelona: Pòrtic.

GUTIÉRREZ ATALA, F. J. (2009): El deber de formación para el periodismo especializado. Madrid: Universidad Complutense de Madrid. Tesis doctoral. Disponible en http://eprints.ucm.es/8783/.

HERRERO, C. (2004): "Géneros para la divulgación periodística", en Fernández del Moral, J. (coord.): Periodismo especializado. Barcelona: Ariel, pp. 171-194.

KNIGHTLEY, P. (2013): "Foreword", en Turner, B. y Orange, R. (eds.): Specialist Journalism. Nueva York: Routledge, pp. xi-xiii.

KOVACH, B. y ROSENSTIEL, T. (2001): Los elementos del periodismo. Madrid: Aguilar, 2012.

LEGAVRE, J. B. (2005): "Les journalistes politiques, des spécialistes du jeu politique", en Matonti, F. (dir.): La démobilisation politique. Paris: La Dispute, pp. 117-142.

MARCHETTI, D. (2002): “Les sous-champs specialisés du journalisme”, La Découverte, no 111, pp. 22-55. DOI: http://dx.doi.org/10.3917/res.111.0022.

MARCHETTI, D. (2005): "Subfields of Specialized Journalism", en Benson, R. y Neveu, E. (eds.): Bourdieu and the journalistic field. Cambridge: Polity Press, pp. 67-82.

MARCHETTI, D. (2008): "El análisis sociológico de la producción de información mediática", Comunicación y Medios, no 18, pp. 19-29.

MARTÍNEZ ALBERTOS, J. L. (1974): Redacción periodística: los estilos y géneros en la prensa escrita. Barcelona: ATE.

MARTÍNEZ NICOLÁS, M. y HUMANES, M. L. (2012): “Culturas profesionales del periodismo político en España. El discurso de los periodistas sobre la política y las funciones políticas de los medios", en Casero-Ripollés, A. (ed.): Periodismo político en España: concepciones, tensiones y elecciones. La Laguna (Tenerife): Sociedad Latina de Comunicación Social, pp. 47-64.

MAZZOLENI, G. (1998): La comunicación política. Madrid: Alianza, 2010.

McILWAINE, S., TANNER, S. y GREEN, K. (2001): “Journalism specialisms: Generating better generalists", Australian Journalism Review, vol. 23, no 1, pp. 171-181.

MENESES, M. D. (2007): "El torno al Periodismo especializado. Consensos y disensos conceptuales", Análisis, no 35, pp. 137-152.

MERCADO SÁEZ, M. T. (2011): “Aportaciones teóricas en torno al concepto de periodismo especializado", Question, vol. 1, no 28, Disponible en https://goo.gl/bsKZ2Q. Consultado el 11 de abril de 2014 . 
MUÑOZ TORRES, J. R. (1997): “Aproximación al concepto de información periodística especializada”, en Esteve, F. (coord.): Estudios sobre información periodística especializada. Valencia: CEU San Pablo, pp. 25-41.

ORIVE RIVA, P. y FAGOAGA, C. (1974): La especialización en el periodismo. Madrid: Dossat.

QUESADA, M. (1995): “La especialización en la prensa diaria de información general”, Periodística, no 8, pp. 75-111.

QUESADA, M. (1998): Periodismo especializado. Madrid: EIUNSA.

QUESADA, M. (2001): “Periodismo Especializado”, en Galdón, G. (coord.): Introducción a la comunicación y la información. Barcelona, Ariel, pp. 123-138.

QUESADA, M. (2004): “Periodismo de investigación: una metodología para el periodismo especializado", en Fernández del Moral, J. (coord.): Periodismo especializado. Barcelona: Ariel, pp. 123-144.

QUESADA, M. (2009): "Fuentes digitales especializadas en contenidos de calidad", en Quesada, M. (ed.) (2010): Internet como fuente generadora de contenidos especializados. Barcelona: UPF, pp. 142-160.

QUESADA, M. (2012): Curso de Periodismo Especializado. Madrid: Síntesis.

RAFTER, K. (2013): "Political journalism", en Turner, B. y Orange, R. (eds.): Specialist Journalism. New York: Routledge, pp. 30-38.

RAMÍREZ DE LA PISCINA, T. (1999): "Realidad y utopía de la especialización en periodismo", Zer, nㅇ 6, pp. 261-279.

RODRÍGUEZ-POLO, X. R. y SANTILLÁN BUELNA, J. R. (2012): “Organización y rutinas del periodismo político en la prensa española de referencia", Observatorio Journal, vol. 6, no 4, pp. 215-234.

SEIJAS CANDELAS, L. R. (2003): Estructura y fundamentos del periodismo especializado. Madrid: Universitas.

SORMANY, P. (2011): Le métier de journaliste. Québec: Boréal.

TORRÓ, J. L. (2013): “Periodismo político", en Cebrián, B. y Mirón, L. (coords.): Áreas del periodismo. Zamora: Comunicación Social, pp. 80-96.

TRESERRAS, J.M. (1994): "Historia de la premsa, història del periodisme, història de la comunicación", en VV.AA.: Gazeta. Actes de les primeres jornades d'historia de la premsa. BarceIona: Societat Catalana de la Comunicació, pp. 67-78.

TUÑEZ LÓPEZ, M. (1999): Producir noticias. Santiago de Compostela: Tórculo.

TUÑóN, A. (1993): "L'especialització en periodisme: un canvi de paradigma”, Anàlisi, no 15, pp. 85-98.

TURNER, B. y ORANGE, R. (eds.) (2013): Specialist journalism. London: Routledge. 
Salvador ENGUIX OLIVER es Licenciado en Ciencias de la Información por la Universitat Autònoma de Barcelona y Doctor en Comunicación por la Universitat de València. Es Delegado del Diario La Vanguardia en la Comunidad Valenciana, diario al que pertenece desde 1991, y del que fue corresponsal en Bruselas durante tres años. También ha trabajado como profesional de la información en RTVV, en los diarios EI País, Mediterráneo, AVUI y Levante-EMV, y en emisoras de radio como la SER y RNE. Desde 1996 es profesor asociado de periodismo de la Universitat de València. En el ámbito de la investigación ha publicado trabajos sobre los mecanismos de encuadre en prensa escrita o sobre la adecuación profesional de los planes de estudio de periodismo en las universidades españolas; en 2015 ha publicado su libro Periodismo político: fundamentos, práctica y perspectivas. Correo electrónico: Salvador.Enguix@uv.es. 